\title{
A 3D Basin Model for Hydrocarbon Potential Evaluation: Application to Congo Offshore
}

\author{
F. Schneider ${ }^{1}$, S. Wolf' ${ }^{1}$, I. Faille' ${ }^{1}$, D. Pot ${ }^{1}$ \\ 1 Institut français du pétrole, 1 et 4, avenue de Bois-Préau, 92852 Rueil-Malmaison Cedex - France \\ e-mail: frederic.schneider@ifp.fr
}

\begin{abstract}
Résumé - Un modèle de bassin 3D pour l'évaluation du potentiel pétrolier : application à l'offshore congolais - La modélisation de bassin 3D est maintenant utilisée par certaines compagnies pétrolières pour conduire leurs activités d'exploration. Les potentialités de cet outil ne sont pas encore complètement explorées, mais il semble qu'il constituerait, à terme, le cœur du processus d'évaluation du potentiel pétrolier des bassins. Nous présentons ici un outil 3D et la méthodologie d'une étude 3D dans une zone relativement mature. La méthodologie est basée sur un processus en quatre étapes qui sont : la construction du bloc 3D, le maillage, la simulation inverse et la simulation directe. Ces étapes seront illustrées au travers d'une étude de cas réalisée dans l'offshore congolais. Les principaux résultats montrent que la migration des hydrocarbures est un processus 3D qui ne peut, dans ce cas, être abordé par une modélisation 2D.
\end{abstract}

Mots-clés : modélisation de bassin, potentiel pétrolier, 3D, Congo.

Abstract - A 3D Basin Model for Hydrocarbon Potential Evaluation: Application to Congo Offshore - 3D basin modelling is now used by some oil companies for exploration purposes. The potentiality of this tool is not fully expressed but it seems that it should become the core of the basin evaluation process in a close future. In this paper, a $3 D$ tool and the methodology of $3 D$ basin modelling in a relatively mature area are presented. The methodology is based on a four-step process: $3 D$ block building, gridding, backward modelling, and forward modelling. These processes are illustrated through a case study performed in the Congo offshore. The main results of this study show that migration is a real $3 D$ process that cannot, in this specific case, be addressed by $2 D$ basin modelling.

Keywords: basin modelling, petroleum potential, 3D, Congo. 


\section{INTRODUCTION}

Integrated basin modelling provides a strategy for optimising exploration in frontier areas and evaluating new plays within well-explored basins. Ideally, a basin simulator should span the entire process of source rock burial, hydrocarbon generation, expulsion, migration into a potential trap, and assessment of trap integrity throughout the evolution of a basin.

1D and 2D basin-modelling tools have been used within oil companies for exploration purposes for approximately ten years (Doligez et al., 1986 ; Ungerer et al., 1990). 1D basin models are useful for the reconstruction of the thermal history of the basin and for the evaluation of the maturation of the organic matter. In sedimentary basin context, the 1D approach is satisfactory for these purposes because the thermal transfers are mostly vertical. Indeed, thermal convective transfers are most frequently negligible. 2D basin models furthermore provide the possibilities of performing an evaluation of the pressure history and appreciating the hydrocarbon migration and reservoir filling. However, these evaluations can only be qualitative because fluid (water, oil and gas) migration is mainly convective and therefore sensitive to $3 \mathrm{D}$ geometry and anisotropy. For these reasons, a basin-modelling tool has been developed. This tool (Temis 3D) allows to simulate in multi$1 \mathrm{D}$ or/and in 3D the thermal history, as well as the pressure evolution and the multiphase flow migration.

A 3D case study is composed of four major steps which are: 3D block building, gridding, backward simulation (restoration) and forward simulation. These different steps will be illustrated through the preliminary results obtained from a case study that has been performed, with data provided by Elf Exploration Production, on a 40-sq-km area located in the Congo offshore (Fig. 1).

\section{3D BLOCK BUILDING}

The 3D block building step consists in defining a coherent 3D block which represents the studied area at present day. This 3D block is obtained by assembling a set of maps with a chronostratigraphic column (Fig. 2). For each of the layers, the given maps are the present-day thicknesses, the present-day bathymetry, the facies distribution, the kerogen distribution and the total organic content (TOC) distribution.

The time is then introduced by giving, for each layer, the paleobathymetry maps, the eroded thickness maps and the boundary conditions, such as the surface temperatures and the basal heat flux. At this step, the spatial resolution of the maps is $500 \times 500 \mathrm{~m}$. The chronostratigraphic column (Table 1) is composed of a list of periods (19 for this study), each of these

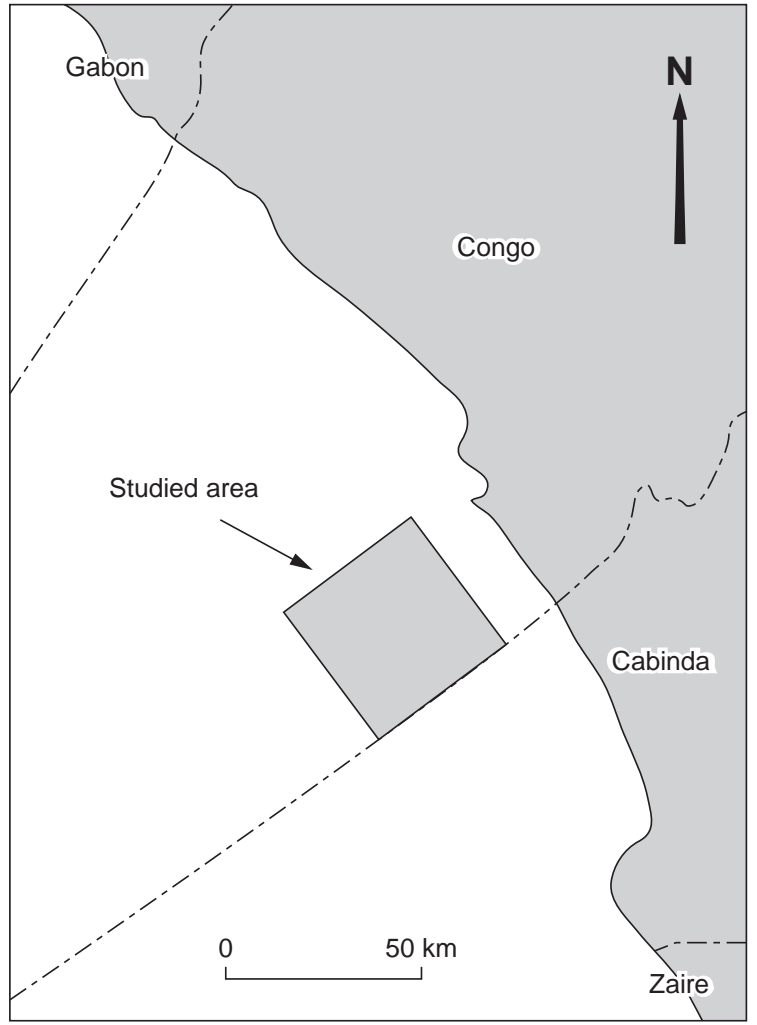

Figure 1

Position of the studied area in the Congo offshore.

TABLE 1

Chronostratigraphic column used for the study presented here (The 3D block is composed of 19 layers (or periods) The simulation begins at $-131 \mathrm{Ma}$ and ends at present day)

\begin{tabular}{l|c|c|c}
\hline \multicolumn{2}{c|}{ Event } & \multicolumn{2}{c}{ Ages (Ma) } \\
\hline Name & Number & From & To \\
\hline Miocene 3rd cycle & 19 & 10.5 & 0.0 \\
Miocene 2nd cycle & 18 & 21.0 & 10.5 \\
Miocene 1st cycle & 17 & 30.0 & 21.0 \\
Erosion & 16 & 33.0 & 30.0 \\
Paleogene & 15 & 66.5 & 33.0 \\
Senonian & 14 & 89.0 & 66.5 \\
Turonian & 13 & 92.0 & 89.0 \\
Upper Cenomanian & 12 & 93.5 & 92.0 \\
Intra Cenomanian seal & 11 & 94.0 & 93.5 \\
Lower Cenomanian & 10 & 96.0 & 94.0 \\
Upper Albian & 9 & 99.5 & 96.0 \\
Lower Middle-Albian & 8 & 108.0 & 99.5 \\
Loeme salt & 7 & 110.0 & 108.0 \\
Chela sandstones & 6 & 113.0 & 110.0 \\
Pointe-Indienne shales & 5 & 115.0 & 113.0 \\
Pointe-Noire marls & 4 & 116.0 & 115.0 \\
Djeno Sandstones & 3 & 121.0 & 116.0 \\
Sialivakou marls & 2 & 127.0 & 121.0 \\
Vandji sandstones & 1 & 131.0 & 127.0 \\
& & & \\
\hline
\end{tabular}




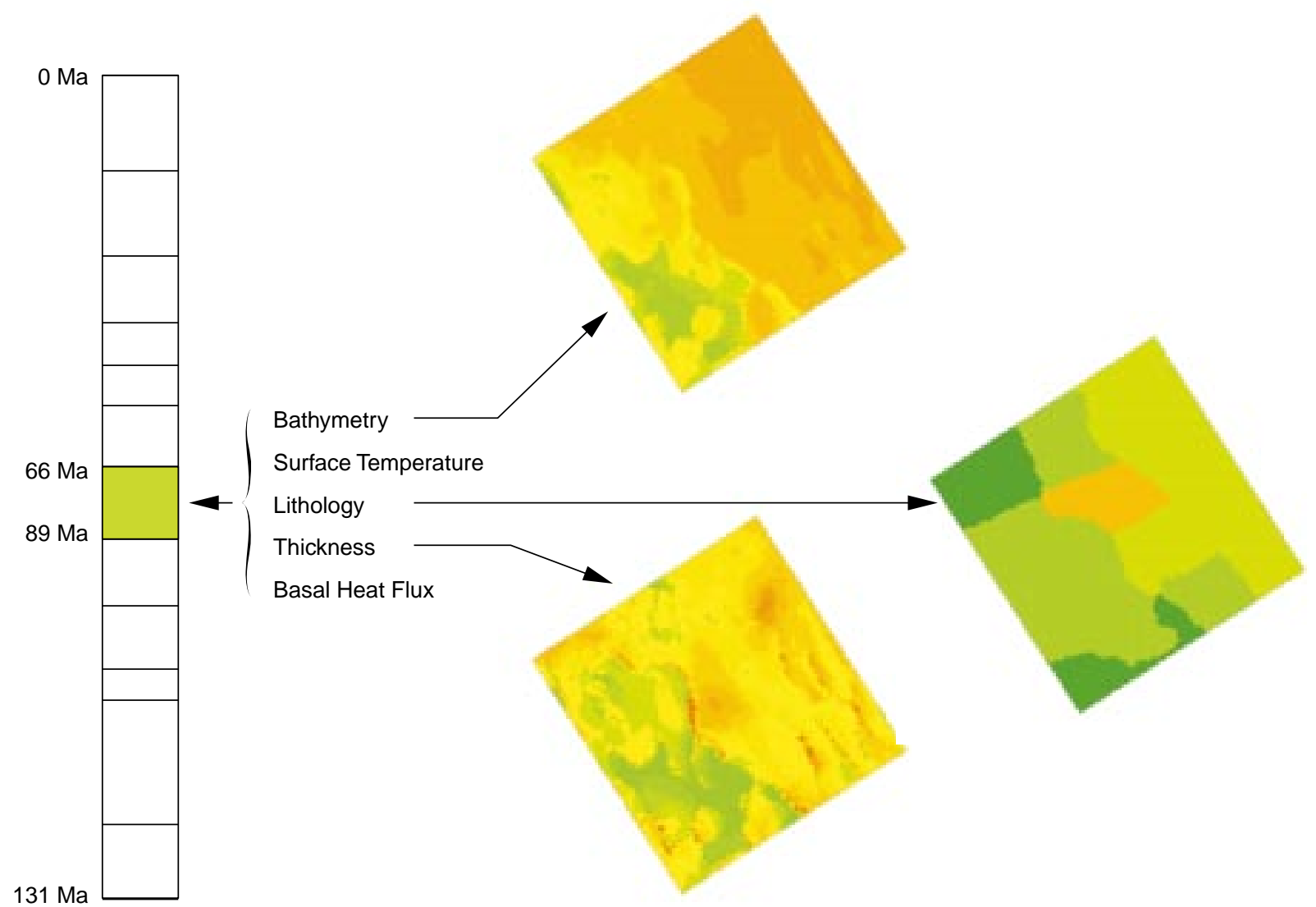

Figure 2

Example of a 3D block composed of a chronostratigraphic column where each time period is correlated with five maps: paleobathymetry, paleotemperature, lithology distribution, thickness at present day, paleoheat flux.

periods being characterised by a number, a beginning age and an ending age. Each period is correlated to one layer in the geometrical 3D block. Once all the previous data are given, the 3D block is terminated and can be visualised as maps, sections or 3D blocks (Fig. 3).

In Figure 3 are represented the main characteristics of the simplified geological model. The main source rocks are the Sialivakou marls of lower Cretaceous Age (Hauterivian). The Pointe-Noire marls (Barremian) and Pointe-Indienne shales (lower Aptian) are also source rocks, even if their potentials are lower than in the Sialivakou marls. These source rocks are covered by the Chela sandstones (middle Aptian), which are a thin $(10 \mathrm{~m})$ regional drain. The Chela sandstones are locally sealed at the bottom by the Loeme salt (upper Aptian). The main known reservoirs are located in the upper Cenomanian and Turonian layers. These reservoir levels are sealed by the Senonian shales which represent a regional seal in this area. Below the source rocks, the Vandji sandstones (Valanginian) may represent a potential reservoir level.

\section{GRIDDING}

Once the surface modelling is terminated, the 3D block should be gridded homogeneously in order to be able to perform either the backward simulations (e.g. backstripping) or the forward simulations. The size of the final gridding is a function of the forward simulator that will be used. Indeed, if the forward simulator is a multi-1D simulator, the original size of the grid $(500 \times 500 \mathrm{~m})$ could be kept; if the forward simulator is a real 3D simulator, the size of the cells should be increased in order to lower the total number of cells. In this study, the final gridding is composed of cells whose size is $900 \times 1100 \mathrm{~m}$ (Fig. 4). The total number of cells is then equal to $54264(51 \times 56 \times 19)$ at the end of the simulation. The total duration of the simulation is $131 \mathrm{Ma}$.

The volumetric model is obtained by building a new set of maps which share the same horizontal grid. The horizontal grid is the vertical projection on a horizontal surface of the points which define the maps. The horizontal grid is built interactively with the help of the existing maps. 


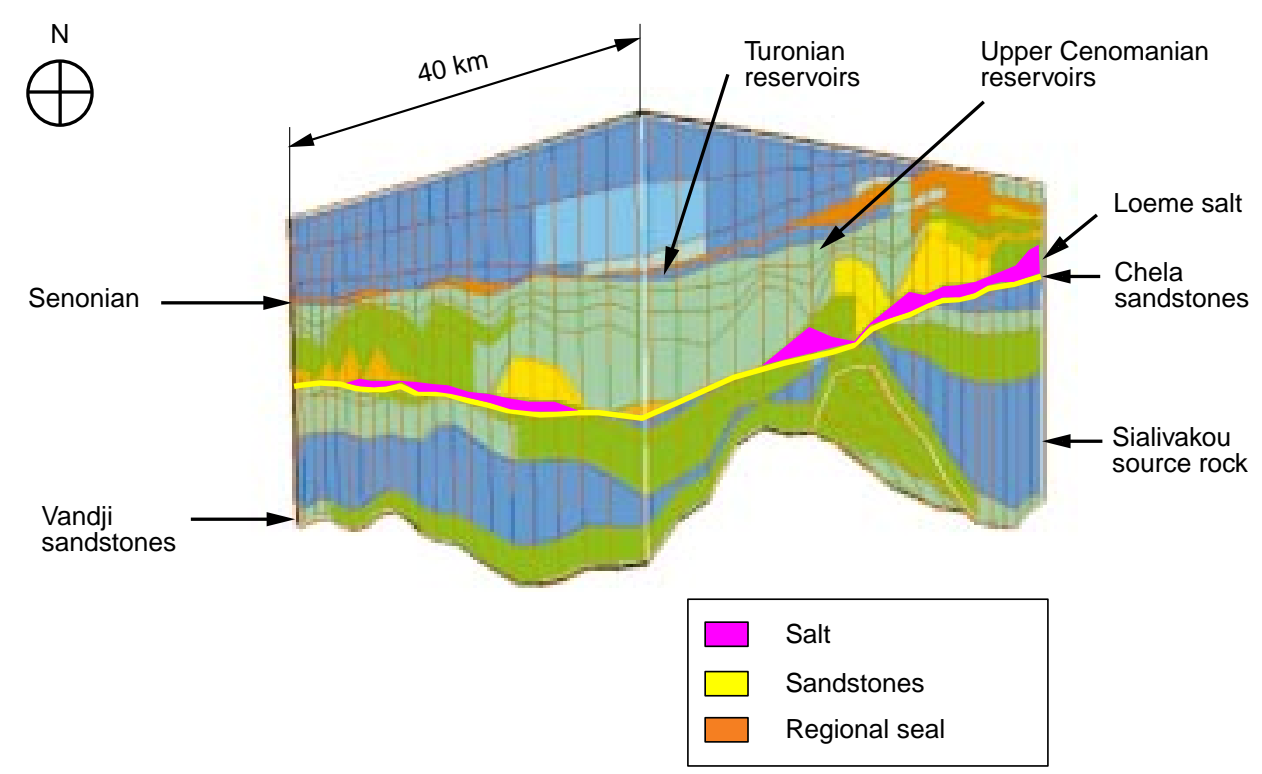

Figure 3

3D visualisation of the 3D block built for the study presented here. The main characteristics of this petroleum system are: the Sialivakou source rocks, the Vandji sandstones, the Chela sandstones, the Loeme salt, the Turonian and upper Cenomanian reservoirs, and the Senonian shales.

\section{BACKWARD SIMULATION}

During this step, the basin geometry evolution through the geological time is inverted with a multi-1D backward simulator. The simulation begins at present day and ends when only the substratum is remaining. In the case presented here, the simulation is finished at $-131 \mathrm{Ma}$.

For each of the periods defined in the chronostratigraphic column, what has been sedimented is taken off and what has been eroded is added to the block. Once the sedimentation and the erosion have been accounted for, the remaining sediments are decompacted, or compacted in case of erosion, by using porosity/depth relationships for each of the lithologies which compose the 3D block.

This process, generally called backstripping (Perrier and Quiblier, 1974), allows to transform the real thickness maps into solid thickness maps (Fig. 5) which are used by all the forward simulators. The solid thickness may be positive for sedimentation, negative for erosion, or null for a hiatus.

\section{FORWARD SIMULATION}

Two kinds of simulations can be performed:

- multi-1D simulations which allow to access the geometrical evolution, the kitchen evaluation, and the petroleum potential appraisal ;

- full-3D simulations which allow to access the overpressure calculations and the hydrocarbon 3D migration and mass balance.
On the one hand, the use of multi-1D forward simulators gives quick results on very fine grid. But there, it implies questionable assumptions, such as the fact that hydrocarbon migration is only vertical, which become untenable when dealing with fluid migration and mass balance.

On the other hand, the use of full-3D forward simulators allows to perform an estimation of the $3 \mathrm{D}$ migration pathways and to determine the hydrocarbon mass balance. But simulations may be long (a few days) and part of the initial spatial resolution may be lost.

\subsection{Multi-1D Simulation}

The present-day geometry of the 3D block to be simulated is built from a set of horizon maps in depth, exported from seismic workstations or interpolated from well data. Restored geometries can be edited by entering erosion and paleotopography maps. Finally, layers are filled with lithologies and their associated petrophysical properties.

The multi-1D geometrical evolution is then computed and the structural traps for each reservoir level are then defined. Each structural trap is automatically identified and mapped, together with its drainage area.

The introduction of the kinetic properties of the source rocks and calculation of the amount of generated and expelled hydrocarbons are performed through an automatic multi-1D simulation. The results consist in maturity maps for each source strata, at every stage of the basin evaluation. 


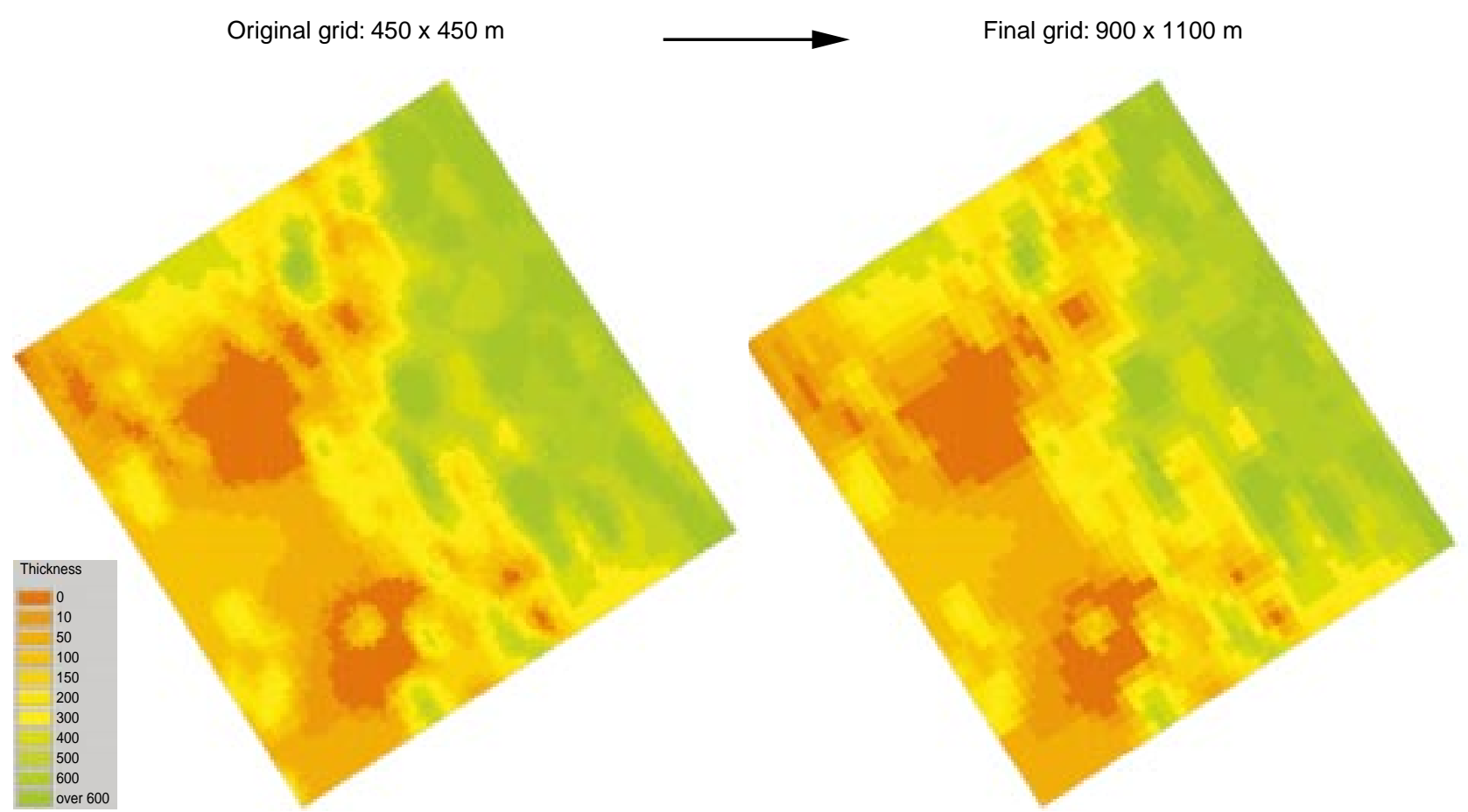

Figure 4

Temis 3D: Gridding. Example of gridding where the original grid $(450 \times 450 \mathrm{~m})$ is transformed into the final grid (900 x $1100 \mathrm{~m})$.

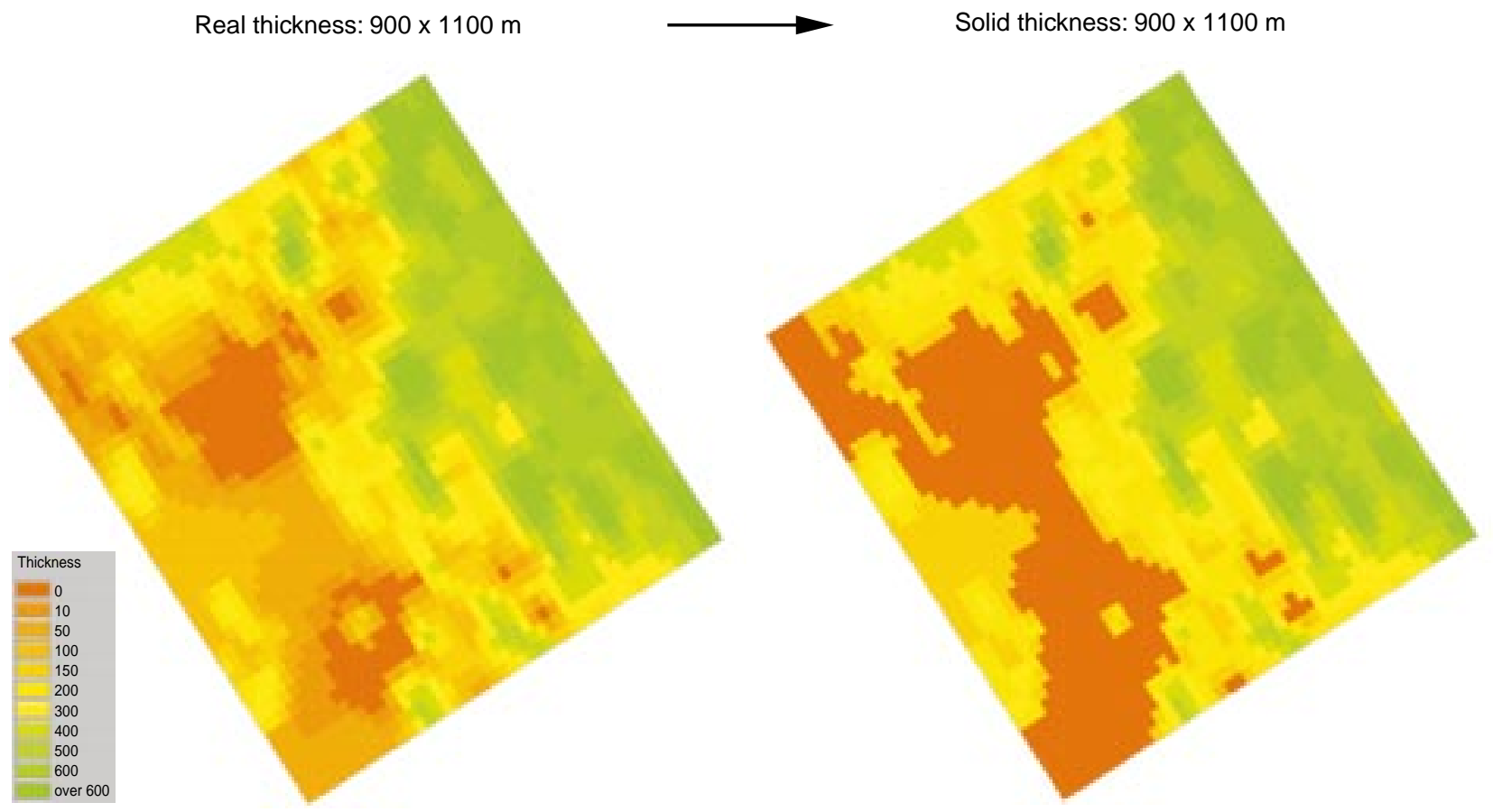

Figure 5

Temis 3D: Backstripping. During the backstripping, the real thickness maps are transformed into solid thickness grids. 
The coupling of information on hydrocarbon production with the drainage area results leads to the evaluation of the petroleum potential for each structural trap. The amount, gas/oil ratio and API gravity of the hydrocarbon charge are also quantified.

\subsection{Full-3D Simulation}

At this step, a fully coupled 3D simulation is performed. Compaction, pressure generation, fluid flow, thermal history, hydrocarbon generation and oil and gas migration are reconstructed in 3D. This final step allows to test the migration pathways, to estimate the reservoir-infilling timing and to assess the mass of oil and gas charge delivered to the traps.

The 3D fluid flow simulator solves simultaneously the mass-conservation equations for solids and fluids, the compaction equation, the momentum-conservation equation, the energy-conservation equation, the maturation equations (three components: oil, gas and coke) and the generalised Darcy's equations (three-phase flow). The physical concepts and their mathematical formulations are described in the Appendix 1, while the compositional cracking of oil, gas and coke is described in Appendix 2.

The previously mentioned equations are solved by using a locally conservative control volume method (Faille, Wolf and Schneider, submitted) using a classical IMPES or a fully implicit scheme for the transport equations. The nonlinearities are treated with a classical Newtonian scheme.

Once the physical parameters and the boundary conditions are fixed, the simulations can begin. Generally, one needs some simulations with feedback from the geophysicists, geologists, and geochemists working in the area before being able to define a reference simulation. Once the reference simulation is approved, in order to account for the uncertainties, some other simulations are needed with different sets of physical parameters and/or boundary conditions. The experience gained during the last years showed that the understanding of a petroleum system is not straightforward. Indeed, hydrocarbon migration is very often a $3 \mathrm{D}$ process which evolves with time, as a result of the coupling between the geometrical evolution and the hydrodynamism.

In the specific simulation presented here, the Sialivakou source rock is overmature everywhere except along a structural high where the organic matter may not be mature in some places (Fig. 6). As a result of a downward expulsion followed by a classical secondary migration, some structural traps are filled with hydrocarbons in the Vandji sandstones (Fig. 7a). Some structural traps of the upper Cenomanian and Turonian layers are filled with hydrocarbons (Figs. $7 b, 7 c$ and $7 d$ ).

The 3D block and the synthetic section presented in Figure 8 illustrate the petroleum system in this area. The source rocks, once they have reached their expulsion threshold, may expel the hydrocarbons downward to the Vandji sandstones, and upward to the Chela sandstones. In the Vandji sandstones, secondary migration occurs until the hydrocarbons are trapped. In the Chela sandstones there are three different configurations:

- there is no salt and the hydrocarbons migrate vertically until they reach the Senonian seal;
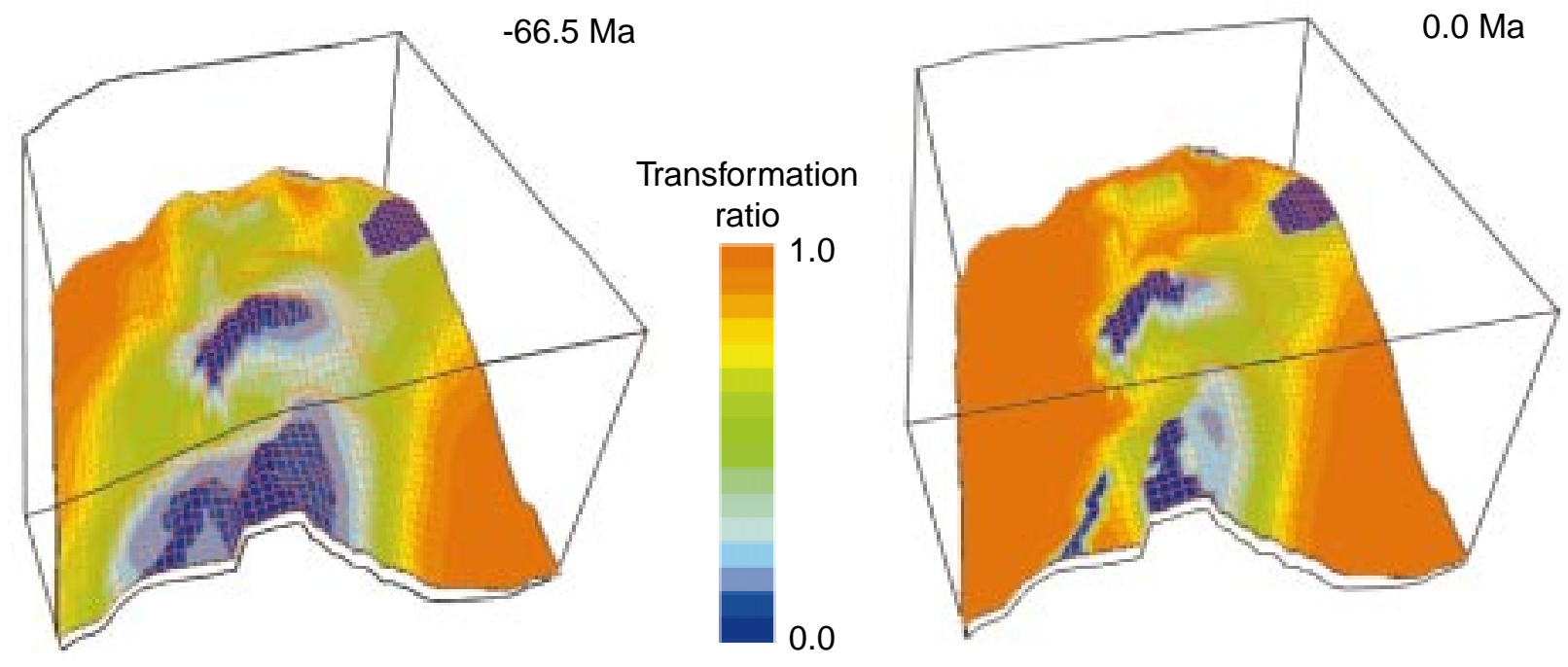

Figure 6

Sialivakou source rocks transformation ratio at $-66.5 \mathrm{Ma}$ and at present day. 

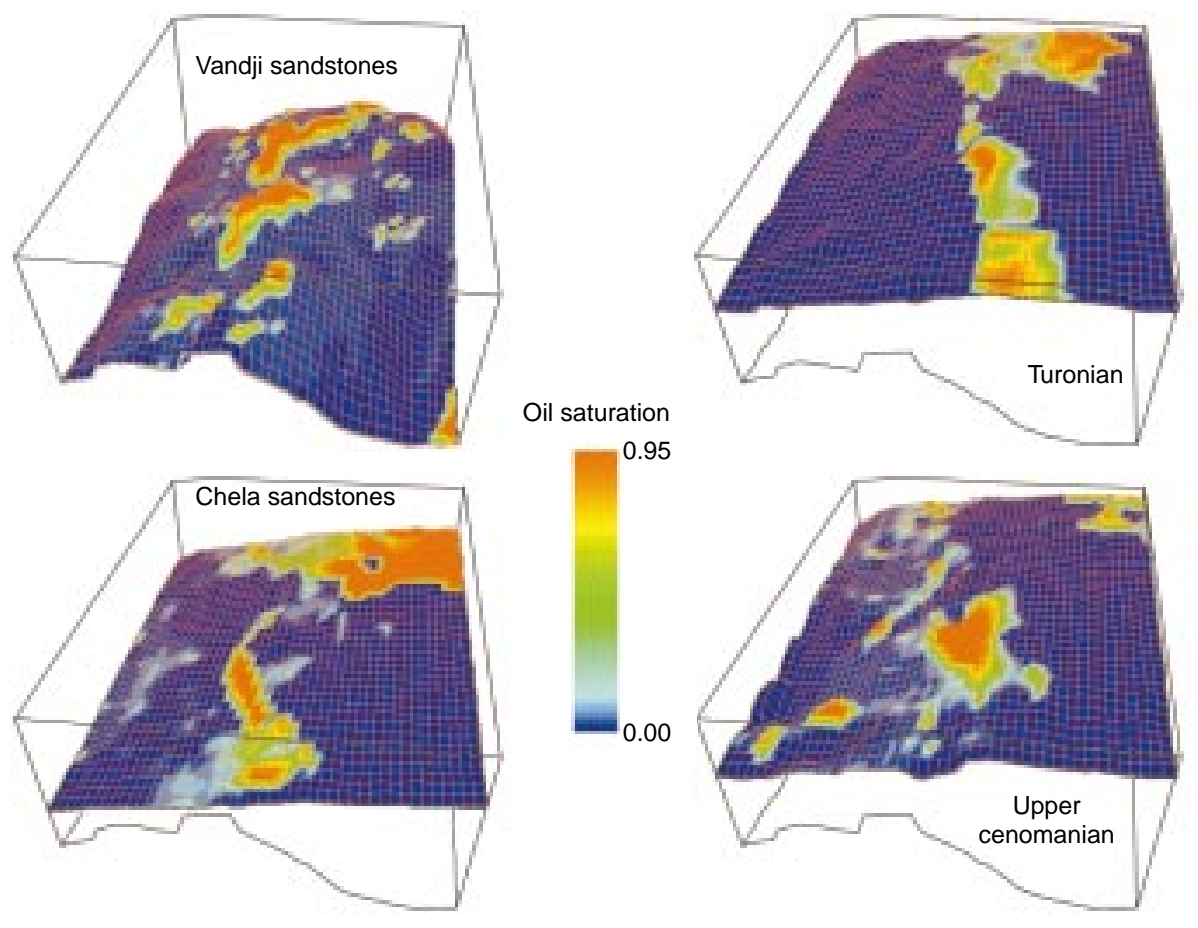

Figure 7

Oil saturation computed for the Vandji sandstones, the Chela sandstones, the Turonian reservoir levels, and the upper Cenomanian reservoir levels.

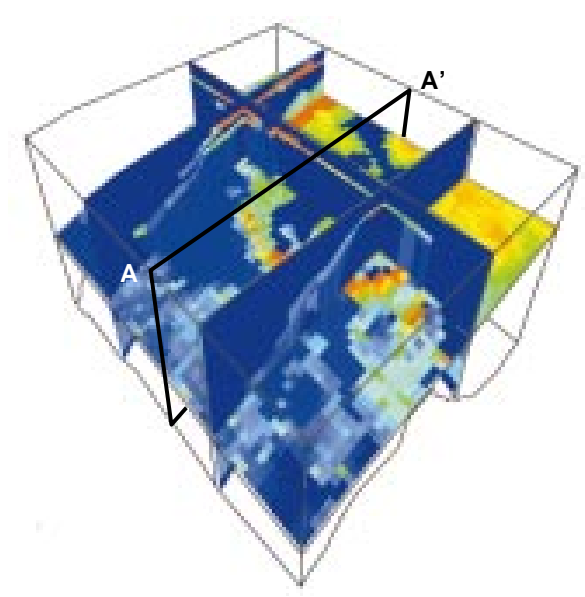

A
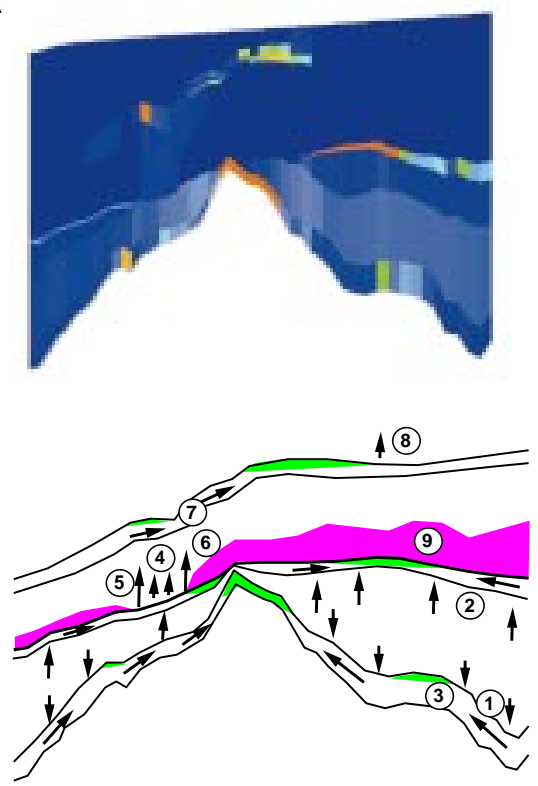

Figure 8

Interpretation of the petroleum system. 1: downward expulsion; 2: upward expulsion; 3: secondary migration in the Vandji sandstones; 4: upward migration through the Chela sandstones where there is no salt; 5: upward leakage after secondary migration in the Chela sandstones below the salt; 6: upward leakage of hydrocarbon trapped in the Chela sandstones below the salt; 7: secondary migration in the Turonian and upper Cenomanian reservoir levels; 8: upward leakage from upper Cenomanian reservoirs; 9: Loeme salt. 
- there is some salt and the hydrocarbons first migrate until they find a hole in the salt, and then migrate vertically until they reach the Senonian seal;

- there is some salt and the hydrocarbons migrate until they are trapped below the salt.

In the third case, the traps created below the salt may leak when filled enough; the hydrocarbons then migrate vertically toward the Senonian seal. These hydrocarbons may be trapped by the lower Cenomanian, the upper Cenomanian or the Turonian reservoir levels. Once guided by these drains, they migrate until they reach a trap.

\section{CONCLUSIONS AND PERSPECTIVES}

Migration of hydrocarbons is a $3 \mathrm{D}$ process that can be efficiently simulated with a 3D basin simulator as the one presented here. Nevertheless, it is easily shown that this 3D process is very sensitive to the $3 \mathrm{D}$ geometry evolution and to the facies distribution.

3D geometry evolution over geological time is a new challenge being addressed by some teams. Unfortunately, the works are generally constrained by structural geology, and not by basin modelling.

Facies distribution is as important as geometry for the prediction of the hydrocarbon migration pathways. This facies distribution is generally obtained from geological and seismic interpretation. Improvements in both fields seem necessary, especially in the domains which are not constrained by wells.

It seems to us that 3D basin modelling should become the core of the basin evaluation for exploration. Indeed, basin modelling is not only, as it used to be, a way to reach consistency between the data provided by all the branches of the exploration, but also a tool to check the quality of the data given in input. Finally, the results of a simulation must be checked against the observations; any misfit could then be used to question some specific input data, such as TOC (Total Organic Content), heat flux, facies distribution, geometry, etc.

\section{ACKNOWLEDGEMENTS}

We wish to thank Elf Exploration Production for permission to publish some results of the Congo offshore study. We also wish to thank C. Cassaigneau and an anonymous reviewer for their contributions to the improvement of the original manuscript.

\section{REFERENCES}

Doligez, B., Bessis, F., Burrus, J., Ungerer, P. and Chenet, P.Y. (1986) Integrated Numerical Simulation of Sedimentation, Heat Transfer, Hydrocarbon Formation and Fluid Migration in a Sedimentary Basin: the Themis Model. Thermal Modelling in Sedimentary Basins, Proceedings of the 1st IFP Research Conference on Exploration, Carcans, June 3-7, 1985, 173-195.

Faille, I., Wolf, S. and Schneider, F. Finite Volume and Finite Element Methods in Basin Modelling (submitted).

Lamoureux-Var, V. (1997) Modélisation de la compaction dans les bassins sédimentaires : approche mécanique. Thesis, École polytechnique.

Perrier, R. and Quiblier, J. (1974) Thickness Changes in Sedimentary Layers during Compaction History; Methods for Quantitative Evolution. AAPG Bull., 58, 3, 507-520.

Schneider, F. (1993) Modèle de compaction élastoplastique en simulation de bassins. Revue de l'Institut français du pétrole, $\mathbf{4 8}$, $1,3-14$.

Schneider, F., Burrus, J. and Wolf, S. (1993) Modelling Overpressures by Effective-Stress/Porosity Relationships in LowPermeability Rocks: Empirical Artifice or Physical Reality?, in Basin Modelling: Advances and Applications, Doré, A.G. et al. (eds.), Elsevier, NPF Special Publication, 3, 333-341.

Schneider, F., Potdevin, J.L., Wolf, S. and Faille, I. (1994) Modèle de compaction élastoplastique et viscoplastique pour simulateur de bassins sédimentaires. Revue de l'Institut français du pétrole, 49, 2, 141-148.

Schneider, F., Potdevin, J.L., Wolf, S. and Faille, I. (1996) Mechanical and Chemical Compaction Model for Sedimentary Basin Simulators. Tectonophysics, 263, 307-317.

Ungerer, P., Burrus, J., Doligez, B. and Bessis, F. (1990) Basin Evaluation by Integrated Two-Dimensional Modelling of Heat Transfer, Fluid Flow, Hydrocarbon Generation and Migration. AAPG Bull., 74, 3, 309-335.

Final manuscript received in June 1999 


\section{APPENDIX 1}

\section{Physical Concepts and Mathematical Formulations}

The origin of the Eulerian coordinates system is given by the present sea level. The $z$ axis is oriented downward.

\section{Mass Balance Equations}

For each phase $\alpha \in\{s, w, o, g\}$ ( $s=$ solid, $w=$ water, $o=$ oil, $g=$ gas), the mass balance equation is:

$$
\operatorname{div}\left(\phi_{\alpha} \rho_{\alpha} \bar{V}_{\alpha}\right)+\frac{f}{f t}\left(\phi_{\alpha} \rho_{\alpha}\right)=\rho_{\alpha} q_{\alpha}
$$

$\phi_{\alpha}$ is the volumetric fraction of the phase $\alpha, \rho_{\alpha}$ is the density of the phase $\alpha, q_{\alpha}$ is the source term corresponding to the phase $\alpha$ and $\bar{V}_{\alpha}$ is the mean velocity of the phase $\alpha$. We have the following relationships:

$$
\phi_{s}+\phi_{w}+\phi_{o}+\phi_{g}=1 \text { and } \phi=\phi_{w}+\phi_{o}+\phi_{g}
$$

where $\phi$ is the porosity of the porous medium. The momentum equation is simplified as follows:

$$
\frac{\partial P_{b}}{\partial z}=\rho_{b} \mathrm{~g}
$$

where $P_{b}$ is the lithostatic pressure (weight of the sedimentary column), $\mathrm{g}$ is the gravity, and $\rho_{b}$ is the bulk density of the porous medium saturated by the fluids. This bulk density is given by:

$$
\left\{\begin{array}{l}
\rho_{b}=\phi_{s} \rho_{s}+\phi \rho_{f} \\
\rho_{f}=\frac{1}{\phi}\left(\phi_{w} \rho_{w}+\phi_{o} \rho_{o}+\phi_{g} \rho_{g}\right)=S_{w} \rho_{w}+S_{o} \rho_{o}+S_{g} \rho_{g}
\end{array}\right.
$$

where $\rho_{f}$ is the mean density of the fluid and $S_{\alpha}$ is the saturation (volumetric fraction) of the phase $\alpha$ in the fluid. The energy equation (or heat equation) is:

$$
\begin{aligned}
q_{h}= & \operatorname{div}\left(\sum_{\alpha}\left(\rho_{\alpha} \phi_{\alpha} C_{\alpha} T \bar{V}_{\alpha}\right)-\lambda_{b} \overline{\operatorname{grad}}(T)\right) \\
& +\frac{\partial}{\partial t}\left(\sum_{\alpha}\left(\rho_{\alpha} \phi_{\alpha} C_{\alpha}\right) T\right)
\end{aligned}
$$

$C_{\alpha}$ is the heat capacity of the phase $\alpha, T$ is the temperature in kelvins, $\lambda_{b}$ is the bulk thermal conductivity of the porous medium saturated by the fluid $\alpha$. It should be noticed that the mechanical energy dissipation is neglected.

\section{Fluid and Porous Medium Rheologies}

The fluid is supposed to obey to the generalised Darcy's laws. Its mathematical formulation is, for each of the phase $\alpha \in\{w, o, g\}$ :

$$
\bar{U}_{\alpha}=\phi_{\alpha}\left(\bar{V}_{\alpha}-\bar{V}_{s}\right)=-\overline{\bar{k}} \eta_{\alpha}\left(\overline{\operatorname{grad}}\left(P_{\alpha}\right)-\rho_{\alpha} \overline{\mathrm{g}}\right)
$$

$\bar{U}_{\alpha}$ is the Darcy's velocity of the phase $\alpha$ in the porous medium, $\overline{\bar{k}}$ is the intrinsic permeability tensor, $\eta_{\alpha}$ is the mobility of the phase $\alpha$ in the porous medium with the other phases, and $P_{\alpha}$ is the pore pressure of the phase $\alpha$.

The intrinsic permeability tensor is written as the product of an anisotropy tensor by the intrisic permeability:

$$
\overline{\bar{k}}=\overline{\bar{a}} k(\phi) \quad \overline{\bar{a}}=\left[\begin{array}{ccc}
a_{s x} & 0 & 0 \\
0 & a_{s y} & 0 \\
0 & 0 & a_{a z}
\end{array}\right]
$$

The intrinsic permeability is computed with the modified Koseny-Carman's formula (Schneider et al., 1996):

$$
k(\phi)=\frac{0.2}{S^{2}} \frac{\phi^{m}}{(1-\phi)^{2}}
$$

where $S$ is the specific surface area of the porous medium.

The mobility of the phase $\alpha$ is given by:

$$
\eta_{\alpha}=\frac{k r_{\alpha}}{\mu_{\alpha}}
$$

The fluid viscosities (water and hydrocarbons) are given by the Andrade's formula:

$$
\mu_{\alpha}(T)=\mu_{\alpha}^{0} \exp \left(b_{\alpha}\left(\frac{1}{T}-\frac{1}{T^{0}}\right)\right)
$$

$T$ is the temperature in kelvins. The triphasic-relative permeabilities are computed from the three diphasic couples of relative permeabilities by using the following formula:

$$
\begin{aligned}
& \left(S_{o}+S_{g}\right) k r_{w}=S_{o} k r_{w o}\left(S_{w}\right)+S_{g} k r_{w g}\left(S_{w}\right) \\
& \left(S_{w}+S_{g}\right) k r_{o}=S_{w} k r_{o w}\left(S_{o}\right)+S_{g} k r_{o g}\left(S_{o}\right) \\
& \left(S_{o}+S_{w}\right) k r_{g}=S_{o} k r_{g o}\left(S_{g}\right)+S_{w} k r_{g w}\left(S_{g}\right)
\end{aligned}
$$

Each of the relative permeability is given by:

$$
\begin{array}{ll}
S_{\alpha} \leq S i_{\alpha \beta} & k r_{\alpha \beta}=0 \\
S i_{\alpha \beta}<S_{\alpha}<1 & k r_{\alpha \beta}=\left(\frac{S_{\alpha}-S i_{\alpha \beta}}{1-S i_{\alpha \beta}}\right)^{p_{\alpha \beta}}
\end{array}
$$

$S i_{\alpha \beta}$ and $P i_{\alpha \beta}$ are characteristic parameters of the porous medium.

This original formalism has been developed for this model in order to be able to account for the possible symmetrical behaviour of each phase and to ensure numerical stability. 
Compaction at basin scale and at geological time scale is supposed to be vertical. This choice is the result of a compromise between accuracy and costs in terms of cpu time (Lamoureux-Var, 1997). The behaviour law is then given by a volumetric rheology (Schneider 1993; Schneider et al., 1994, 1996):

$$
\begin{aligned}
& \int \frac{d_{s} \phi}{d t} \quad=-\beta(\sigma) \frac{d_{s} \sigma}{\mathrm{d} t}-\alpha(\phi) \sigma \\
& \beta(\sigma) \quad=\frac{\phi_{a}}{E_{a}} \exp \left(-\frac{\sigma}{E_{a}}\right)+\frac{\phi_{b}}{E_{b}} \exp \left(-\frac{\sigma}{E_{b}}\right) \quad \sigma \geq \sigma_{m} \\
& \beta(\sigma) \quad=\frac{1}{E_{e}} \\
& \alpha(\phi) \quad=(1-\phi) \frac{1}{\mu_{b}(T)} \\
& \alpha(\phi) \quad=0 \\
& \phi(t=0)=\phi_{r}+\phi_{a}+\phi_{b} \\
& \sigma<\sigma_{m} \\
& \sigma>0 \text { and } \phi>\phi^{\mathrm{min}} \\
& \sigma \leq 0 \text { or } \phi \leq \phi^{\min }
\end{aligned}
$$

where $\sigma$ is the mean effective stress defined as follows:

$$
\begin{aligned}
& \sigma=\left(\frac{1+2 K_{o}}{3}\right)\left(P_{b}-b P_{f}\right) \\
& P_{f}=\frac{1}{\phi}\left(\phi_{w} P_{w}+\phi_{o} P_{o}+\phi_{g} P_{g}\right)=S_{w} P_{w}+S_{o} P_{o}+S_{g} P_{g}
\end{aligned}
$$

where $P_{f}$ is the mean pore pressure, and $b$ the effective stress coefficient (Schneider, Burrus and Wolf, 1993). The pore pressure of each of the phases is related to each other by the capillary pressures:

$$
\left\{\begin{array}{l}
P_{o}=P_{w}+P c_{o w} \\
P_{g}=P_{w}+P c_{g w} \\
P_{g}=P_{o}+P c_{g o}
\end{array}\right.
$$

If we make the assumption that the water phase is always present, this means that the porous medium is water-wet, only the two first relations are necessary since we can write:

$$
P c_{g o}=P c_{g w}-P c_{o w}
$$

Introducing the mean pore pressure, we obtain:

$$
\left\{\begin{array} { l } 
{ P _ { w } = P _ { f } + P c _ { w f } } \\
{ P _ { o } = P _ { f } + P c _ { o f } } \\
{ P _ { g } = P _ { f } + P c _ { g f } }
\end{array} \quad \text { with } \quad \left\{\begin{array}{l}
P c_{w f}=-S_{o} P c_{o w}-S_{g} P c_{g w} \\
P c_{o f}=+S_{w} P c_{o w}-S_{g} P c_{g o} \\
P c_{g f}=+S_{w} P c_{g w}+S_{o} P c_{g o}
\end{array}\right.\right.
$$

Under the assumption that water is always present, we can write:

$$
\left\{\begin{array}{l}
P c_{w f}=-S_{o} P c_{o w}-S_{g} P c_{g w} \\
P c_{o f}=+\left(1-S_{o}\right) P c_{o w}-S_{g} P c_{g w} \\
P c_{g f}=-S_{o} P c_{o w}+\left(1-S_{g}\right) P c_{g w}
\end{array}\right.
$$

As for the relative permeabilities, the triphasic capillary pressures are derived from the diphasic capillary pressures. With the assumption that water is always present, only the oil-water and the gas-water capillary pressure curves are necessary. They are given by the following formula:

$$
\begin{aligned}
& \tilde{S}_{\alpha} \leq S i_{\alpha \beta} \quad P c_{\alpha \beta}=P c 1_{\beta \alpha} \\
& S i_{\alpha \beta}<\tilde{S}_{\alpha}<1-S i_{\beta \alpha} \\
& \qquad P c_{\alpha \beta}=P c 1_{\beta \alpha}+\left(P c 1_{\alpha \beta}-P c 1_{\beta \alpha}\right)\left(\frac{\tilde{S}_{\alpha}-S i_{\alpha \beta}}{1-S i_{\beta \alpha}-S i_{\alpha \beta}}\right)^{\gamma_{\alpha \beta}} \\
& \quad P c_{\alpha \beta}=P c 1_{\alpha \beta} \\
& \tilde{S}_{\alpha} \leq S i_{\beta \alpha} \\
& \text { with } \tilde{S}_{\alpha}=\frac{S_{\alpha}}{S_{\alpha}+S_{\beta}} \text { and } 0<\gamma_{\alpha \beta} \leq 1 \text {, where } \alpha_{\alpha \beta} \\
& \text { is a characteritic parameter of the porous medium. }
\end{aligned}
$$

\section{State Equations}

The density of each phase is given by:

$$
\rho_{\alpha}=\rho_{\alpha}^{0} \exp \left(\alpha_{\alpha}\left(T-T_{\alpha}^{0}\right)+\beta_{\alpha}\left(P_{\alpha}-P_{\alpha}^{0}\right)\right)
$$

\section{Closure of the Problem}

The problem consists in the resolution of a system composed of 13 equations with the 13 unknowns $\phi_{\alpha}, \bar{V}_{\alpha}, P_{\alpha}, T$. Once the boundary conditions are given, the system is well posed.

\section{Boundary Conditions}

At the upper boundary, the pressures are imposed by the atmospheric pressure and by the bathymetry. The displacements are imposed by the bathymetry. And the temperatures are imposed.

At the lower boundary, there is no fluid flux and the displacements are free. The heat fluxes are imposed.

At the vertical edges, there is no fluid nor heat flux, the displacements are only vertical.

\section{APPENDIX 2}

\section{Hydrocarbon Generation}

The hydrocarbon generation is performed with a conservative physical model which considers three components (oil, gas and coke). In this model, the oil component is entirely in the hydrocarbon liquid phase, the gas component is entirely in the hydrocarbon vapour phase, and the water component is entirely in the water phase.

\section{Description of the Porous Medium}

The porous medium is composed of immobile components (solid, kerogen and coke) and mobile components (oil, gas and water). 


\begin{tabular}{cc|c|c|c|c}
\hline \multicolumn{2}{l|}{ Component } & $\begin{array}{c}\text { Den- } \\
\text { sity }\end{array}$ & $\begin{array}{c}\text { Volu- } \\
\text { metric } \\
\text { fraction }\end{array}$ & Volume & Mass \\
\hline Immobile & Solid & $\rho_{s}$ & $1-\phi$ & $\operatorname{Vol}_{s}=\operatorname{Vol}_{b}(1-\phi)$ & $M_{s}=\operatorname{Vol}_{s} \rho_{s}$ \\
& Kerogen & $\rho_{k}$ & $\phi S_{k}$ & $\operatorname{Vol}_{k}=\operatorname{Vol}_{b} \phi S_{k}$ & $M_{k}=\operatorname{Vol}_{k} \rho_{k}$ \\
Coke & $\rho_{c}$ & $\phi S_{c}$ & $\operatorname{Vol}_{c}=\operatorname{Vol}_{b} \phi S_{c}$ & $M_{c}=\operatorname{Vol}_{c} \rho_{c}$ \\
\hline Mobile & Oil & $\rho_{o}$ & $\phi S_{o}$ & $\operatorname{Vol}_{o}=\operatorname{Vol}_{b} \phi S_{o}$ & $M_{o}=\operatorname{Vol}_{o} \rho_{o}$ \\
& Gas & $\rho_{g}$ & $\phi S_{g}$ & $\operatorname{Vol}_{g}=\operatorname{Vol}_{b} \phi S_{g}$ & $M_{g}=\operatorname{Vol}_{g} \rho_{g}$ \\
& Water & $\rho_{w}$ & $\phi S_{w}$ & $\operatorname{Vol}_{w}=\operatorname{Vol}_{b} \phi S_{w}$ & $M_{w}=\operatorname{Vol}_{w} \rho_{w}$ \\
\hline
\end{tabular}

The porous medium is characterised by its initial composition. We make the assumption that the initial existing components are the solid, the water and the kerogen. The initial porosity is given by the behaviour law (Appendix 1). The initial mass of kerogen is introduced by the TOC (Total Organic Content) which is given in grams of organic carbon per gram of dry rock.

We admit that the TOC is given by the following formula:

$$
\mathrm{TOC}=\frac{c M_{k}^{0}}{M_{k}^{0}+M_{s}^{0}}
$$

where $c$ is the mass carbon ratio of the kerogen, and a characteristic datum of the kerogen.

\section{Primary Cracking}

During the primary cracking, the kerogen is transformed with $n$ parallel reactions into oil, gas and coke:

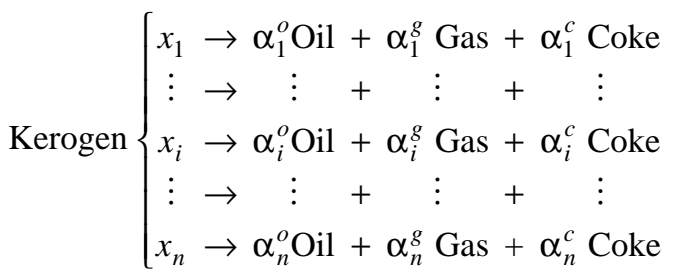

$x_{i}$ is the normalised partial potential of reaction $i$. It is a datum of the kerogen and obeys to the following relation:

$$
\sum_{i=1}^{n} x_{i}^{0}=1
$$

$\alpha_{i}^{o}$ (respectively $\alpha_{i}^{g}$ et $\alpha_{i}^{c}$ ) is the oil (respectively the gas and coke) quantity produced by the reaction $i$. We have:

$$
\alpha_{i}^{o}+\alpha_{i}^{g}+\alpha_{i}^{c}=1
$$

Each of these elementary reactions is supposed to be controlled by a first-order kinetic given by the following equation:

$$
\frac{\mathrm{d} x_{i}}{\mathrm{~d} t}=-k_{i} x_{i} \quad \text { with } \quad k_{i}=A_{i} \exp \left(-\frac{E_{i}}{\mathrm{R} T}\right)
$$

$A$ is the frequency factor. $E$ is the activation energy. $\mathrm{R}$ is the perfect gas constant. $T$ is the temperature in kelvins.

\section{Secondary Cracking}

The oil produced by the primary cracking is then transformed, during the secondary cracking, into gas and coke. This reaction is supposed to be controlled by a firstorder kinetic given by the following equation:

$$
\text { Oil } \rightarrow \beta_{o}^{g} \text { Gas }+\beta_{o}^{c} \text { Coke } \quad k_{o}=A_{o} \exp \left(-\frac{E_{o}}{\mathrm{R} T}\right)
$$

$\beta_{o}^{g}$ and $\beta_{o}^{c}$ are the stoechiometric coefficients of the reaction, and respect the following condition:

$$
\beta_{o}^{g}+\beta_{o}^{c}=1
$$

\section{Transformation Ratio}

The equations which describe the primary cracking are discretised with an implicit scheme for the partial potential and with explicit temperatures. Thus, we have:

$$
\frac{\mathrm{d} x_{i}}{\mathrm{~d} t}=-k_{i} x_{i} \Rightarrow x_{i}^{n+1}=\frac{x_{i}^{n}}{1+k_{i}^{n} \delta t}
$$

$\delta t$ is the time step. The $n$ exponent indicates values taken at $t$, while the $n+1$ exponent indicates values taken at $t+\delta t$. The transformation ratio (TR) of the organic matter is then given by:

$$
\mathrm{TR}=1-\sum_{i=1}^{n} x_{i}^{n+1}
$$

